\title{
Neuromuscular Dysfunction in Experimental Sepsis and Glutamine
}

\author{
İlkin Çankayalı, Özden Boyacılar, Kubilay Demirağ, Mehmet Uyar, Ali Reşat Moral
}

Department of Anesthesiology and Intensive Care, Ege University School of Medicine, İzmir, Turkey

Background: Electrophysiological studies show that critical illness polyneuromyopathy appears in the early stage of sepsis before the manifestation of clinical findings. The metabolic response observed during sepsis causes glutamine to become a relative essential amino acid.

Aims: We aimed to assess the changes in neuromuscular transmission in the early stage of sepsis after glutamine supplementation.

Study Design: Animal experimentation.

Methods: Twenty male Sprague-Dawley rats were randomized into two groups. Rats in both groups were given normal feeding for one week. In the study group, $1 \mathrm{~g} / \mathrm{kg} /$ day glutamine was added to normal feeding by feeding tube for one week. Cecal ligation and perfora- tion (CLP) surgery was performed at the end of one week. Before and 24 hours after CLP, compound muscle action potentials were recorded from the gastrocnemius muscle.

Results: Latency measurements before and 24 hours after CLP were $0.68 \pm 0.05 \mathrm{~ms}$ and $0.80 \pm 0.09 \mathrm{~ms}$ in the control group and $0.69 \pm 0.07 \mathrm{~ms}$ and $0.73 \pm 0.07 \mathrm{~ms}$ in the study group $(\mathrm{p}<0.05)$.

Conclusion: Since enteral glutamine prevented compound muscle action potentials (CMAP) latency prolongation in the early phase of sepsis, it was concluded that enteral glutamine replacement might be promising in the prevention of neuromuscular dysfunction in sepsis; however, further studies are required.

Keywords: Experimental, glutamine, neuromuscular, sepsis
Neuromuscular dysfunction (NMD) observed in intensive care unit patients leads to difficulty in "weaning" from mechanical ventilation and is associated with high rates of mortality and morbidity. Myopathic changes termed critical illness myopathy (CIM) also occur in some cases in addition to critical illness polyneuropathy (CIP) which is considered to be a neurological component of sepsis and characterized by demyelination and axonal degeneration (1). The frequency of these neuromuscular disorders, which are known as critical illness polyneuromyopathy (CIPNM) in systemic inflammatory response syndrome (SIRS) and sepsis patients, ranges from $50-70 \%$. CIPNM is clinically diagnosed only in the late stages of the disease. However, electrophysiological studies show that the findings of CIPNM appear in the early stage of sepsis before the manifestation of clinical findings $(2,3)$. Decreased amplitude, latency prolongation and a decline in nerve conduction velocity are the electrophysiological findings that call attention in the early phase of sepsis $(2,3)$.

Unavoidable catabolic stress seen in sepsis is associated with high levels of oxidative stress reduction in protein mass and antioxidant capacity, intestinal immune barrier dysfunction and immunodeficiency. Amino acids which are stored and released from the skeletal muscles when required, in particular glutamine, which is synthesized and stored in the skeletal muscle, are depleted during the synthesis of acute phase proteins (C-reactive protein, alpha-1-acid glycoprotein, fibrinogen etc.) and gluconeogenesis.

A reduction is seen in muscle mass, muscle strength and muscle activity due to erosion in the skeletal muscles as well as the depletion of the amino acids $(4,5)$. Electromyographic studies and muscle biopsies demonstrate that myosinolysis occurs along with necrosis and muscle atrophy in type II fibers (6-8).

This study was presented as an oral preseantation at the $34^{\text {th }}$ Congress of the European Society of Clinical Nutrition and Metabolism (ESPEN 2012), 8-11 September 2012, Barcelona, Spain.

Address for Correspondence: Dr. Illkin Çankayal, Department of Anesthesiology and Intensive Care, Ege University School of Medicine, İzmir, Turkey

Phone: +90 5423135546 e-mail: ilkin.cankayali@ege.edu.tr

Received: 6 June 2014 Accepted: 26 June 2015 - DOI: 10.5152/balkanmedj.2016.140483

Available at www.balkanmedicaljournal.org 
Glutamine, which is synthesized in the skeletal muscle via the enzyme glutamine synthetase, is the most abundant nonessential amino acid found in the body and stored within the skeletal muscles. The metabolic response observed during sepsis causes glutamine to become a relatively essential amino acid (9). While skeletal muscles decrease in sepsis, depletion and requirement of glutamine increase $(9,10)$. In addition, glutamine levels in skeletal muscle reduce.

The decreased glutamine level in the striated muscles causes intracellular shrinkage and dryness in the tissues of the striated muscles, causing changes in anabolic and catabolic behaviors of the cell and activation of Adenosine monophosphate-activated protein kinase (AMPK) $(11,12)$.

It has been highlighted with greater emphasis in recent years that metabolic and especially nutritional factors need to be investigated with regard to the development and prevention of NMD in the sepsis associated with increased protein catabolism and loss of striated muscle mass.

Therefore, in our study, our aim was to assess changes in the neuromuscular transmission that develop in the early stage of sepsis with enteral glutamine replacement by using electrophysiological recordings.

\section{MATERIALS AND METHODS}

The study was initiated after obtaining approval from the Animal Ethics Committee of Ege University School of Medicine.

Before and during the study, all of the rats were housed in cages in an acclimatized room at standard room temperature by allowing free access to water and standard chow with $12 \mathrm{hr}$ light/dark cycles.

During the procedures of electrophysiological recordings and orogastric tube (feeding tube) insertion, rats were anesthetized using intraperitoneal (IP) injection of Ketamine 100 $\mathrm{mg} / \mathrm{kg}$ and IP injection of Xylazine $10 \mathrm{mg} / \mathrm{kg}$.

The study was performed on 20 adult Wistar rats: 10 male and 10 female rats, each weighing approximately $250 \mathrm{~g}$ rats were randomly divided into 2 equal groups.

\section{Groups}

Group I $(\mathrm{n}=10)$ : Sepsis group (cecal ligation and puncture (CLP) surgery + normal feeding) Rats in group 1 were given normal feeding and CLP surgery was performed under anesthesia at the end of week one.

Group II $(n=10)$ : Sepsis+glutamine group (CLP surgery + normal feeding $+1 \mathrm{~g} / \mathrm{kg} /$ day enteral glutamine); (Glutamine Resource, Nestle)

To maximize glutamine stores prior to performing the CLP procedure, rats in group 2 were given $1 \mathrm{~g} / \mathrm{kg}$ /day enteral gluta- mine by orogastric tube (feeding tube) for one week in addition to normal feeding and then CLP surgery was performed under anesthesia.

\section{Constitution of sepsis model}

Sepsis was induced by the CLP model which was performed beforehand in different researches $(13,14)$. After the administration of anesthesia under septic conditions, a $2 \mathrm{~cm}$ midline incision was made. After laparotomy, the cecum was ligated with a 3.0 silk suture at its base and perforated once with a 22-gauge needle. The cecum was gently squeezed to extrude a small amount of feces from the perforation site. Then, the cecum was returned to the peritoneal cavity and the laparotomy incision was closed with 3.0 silk sutures. During the procedure, all of the rats were resuscitated using an IP injection of $10 \mathrm{~mL} / \mathrm{kg}$ of normal saline.

\section{Electrophysiological recordings}

Electrophysiological recordings of the rats under anesthesia were obtained from the left sciatic nerve stimulated supramaximally at the notch (intensity $10 \mathrm{~V}$. duration $0.1 \mathrm{~ms}$. frequency $1 \mathrm{~Hz}$ ) (Stimulator: SS2L Electrode and BSLSTMA Trigger BIOPAC System. Inc.; Santa Barbara, USA). HSTM01 superficial disc electrodes (BIOPAC System Inc., Santa Barbara, USA) were used for electrical stimulation. Compound muscle action potential (CMAP) of the gastrocnemius muscle was monitored (Figure 1-4).

Compound Muscle Action Potentials are accepted motor and sensory components of peripheral nerves. It is used as an electrodiagnostic test in animals, where amplitude, latency and duration are evaluated (2,3,15-18).

Latency, amplitude and total duration parameters of CMAP were calculated using the Biopac Student Lab Pro software (BIOPAC Data MP35 Acquisition System; BIOPAC Systems Inc; Santa Barbara, USA) and displaying them in the digital environment. The mean value of five CMAP waves calculated for each rat was taken (Figure 1-4).

Changes in CMAP values (latency, amplitude and duration) within each group before and after laparotomy at the end of the study were evaluated in the Department of Biostatistics and Medical Informatics in Ege University School of Medicine. "Analysis of variance" was used for repeated measures, the "t-test" was used for the comparison of two groups with independent baseline values, and the "paired t-test" was used for the evaluation of change from the baseline values in each of the groups. A value of $\mathrm{p}<0.05$ was considered to be statistically significant.

PASW Statistics 18 (formerly SPSS Statistics, SPSS Inc.; Rm 1804, 18/F, Westlands Centre, Westlands Road, Quarry Bay, Hong Kong) was used. 


\section{RESULTS}

Two rats died at the end of the first 24 hours in both groups.

There was no statistically significant difference in the weights of the rats in all groups.

(Observed power $=54.1 \%$ ).

While preoperative CMAP latency was $0.68 \pm 0.05 \mathrm{~ms}$ in the sepsis group, it was found to be $0.80 \pm 0.09 * \mathrm{~ms}$ at the end of 24 hours after surgery, and the difference was statistically significant $(\mathrm{p}<0.05)$ (Table 1, Figure 1, 2).

While preoperative CMAP latency was $0.69 \pm 0.07 \mathrm{~ms}$ in the glutamine group, it was found to be $0.73 \pm 0.07 \mathrm{~ms}$ at the end of 24 hours after surgery, and the difference was not statistically significant (Table 1, Figure 3, 4).

While preoperative CMAP amplitude was $10.05 \pm 1.05 \mathrm{mV}$ in the sepsis group, it was found to be $9.89 \pm 0.97 \mathrm{mV}$ at the end of 24 hours after surgery and the difference was not statistically significant (Table 1, Figure 1, 2).
While preoperative CMAP amplitude was $10.22 \pm 0.90 \mathrm{mV}$ in the glutamine group, it was found to be $10.26 \pm 0.77 \mathrm{mV}$ at the end of 24 hours after surgery, and the difference was not statistically significant (Table 1, Figure 3, 4).

While preoperative CMAP duration was $8.40 \pm 1.53 \mathrm{~ms}$ in the sepsis group, it was found to be $8.38 \pm 0.86 \mathrm{~ms}$ at the end of 24 hours after surgery, and the difference was not statistically significant (Table 1, Figure 1, 2).

While preoperative CMAP duration was $9.24 \pm 0.59 \mathrm{~ms}$ in the glutamine group, it was found to be $9.43 \pm 0.50 \mathrm{~ms}$ at the end of 24 hours after surgery, and the difference was not statistically significant (Table 1, Figure 3, 4).

During the measurements performed at the end of 24 hours, as expected in Group I, it was observed that CMAP latency prolongation was statistically significant, whereas there was no statistically significant difference in Group II in which enteral glutamine replacement was performed (Table 1, Figure 1-4).

TABLE 1. Measurements of compound gastrocnemius muscle action potentials

\begin{tabular}{|c|c|c|c|c|c|c|}
\hline & \multicolumn{2}{|c|}{ Latency (ms) } & \multicolumn{2}{|c|}{ Amplitude (mV) } & \multicolumn{2}{|c|}{ Duration (ms) } \\
\hline & $0^{\text {th }}$ hour $(\mathrm{n}=10)$ & $24^{\text {th }}$ hour $(\mathrm{n}=8)$ & $0^{\text {th }}$ hour $(\mathrm{n}=10)$ & $24^{\text {th }}$ hour $(n=8)$ & $0^{\text {th }}$ hour $(\mathrm{n}=10)$ & $24^{\text {th }}$ hour $(n=8)$ \\
\hline Group I & $0.68 \pm 0.05$ & $0.80 \pm 0.09^{*}$ & $10.05 \pm 1.05$ & $9.89 \pm 0.97$ & $8.40 \pm 1.53$ & $8.38 \pm 0.86$ \\
\hline Group II & $0.69 \pm 0.07$ & $0.73 \pm 0.07$ & $10.22 \pm 0.90$ & $10.26 \pm 0.77$ & $9.24 \pm 0.59$ & $9.43 \pm 0.50$ \\
\hline
\end{tabular}

All values are mean \pm SD for each group.

${ }^{*} \mathrm{p}<0.05$ (compared to baseline value).

ms: millisecond; $\mathrm{mV}$ : milivolt

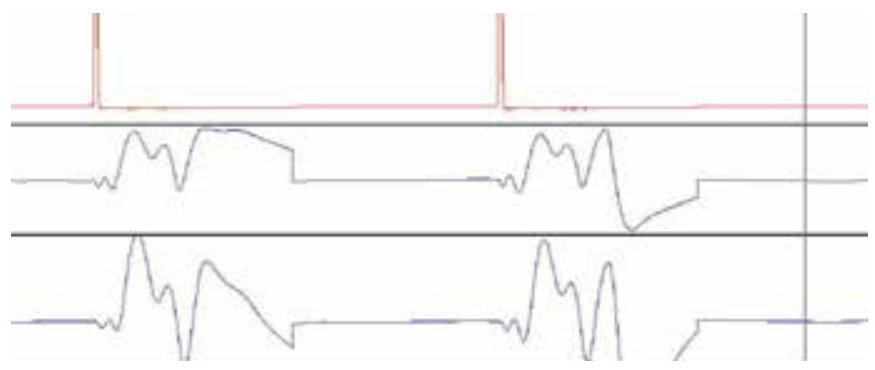

FIG. 1. A sample of compound muscle action potential recorded 24 hours before sepsis in Group I

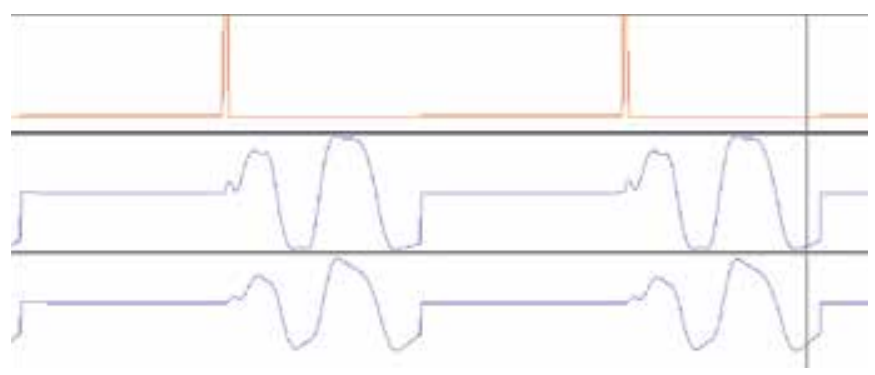

FIG. 2. A sample of compound muscle action potential recorded 24 hours after sepsis in Group I



FIG. 3. A sample of compound muscle action potential recorded 24 hours before sepsis in Group II

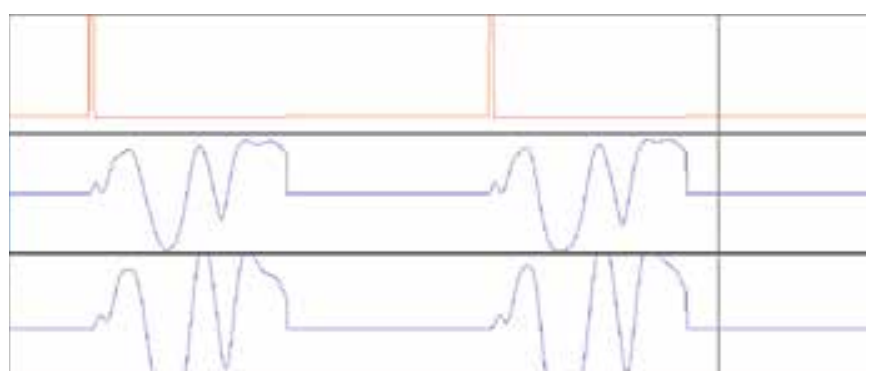

FIG. 4. A sample of compound muscle action potential recorded 24 hours after sepsis in Group II 


\section{DISCUSSION}

Critical illness polyneuropathy resulting from disturbances in microcirculation and auto-regulation of peripheral sensory/ motor nerves in a background of SIRS and sepsis is associated with primary axonal neuropathy and is considered to be an important cause of neuromuscular dysfunction seen in sepsis $(6,19-21)$. Cytokines released during sepsis also cause an increase in capillary permeability due to a histamine-like effect $(20,21)$. The resulting endoneural edema leads to hypoxia and energy deficit by deteriorating diffusion in the intercapillary space since the axonal transportation of structural proteins is highly energy-dependent. This energy deficit induces primary axonal degeneration of the distal nerves (20). Bolton et al. (21) suggested that the release of tumor necrosis factor (TNF), arachidonic acid, and metabolites of histamine, which are considered to be the principal factors responsible for systemic effects of sepsis and SIRS, as well as complement activation cellular adhesion systems, proinflammatory cytokines and free oxygen radicals might lead to primary axonal degeneration. Also, muscular dysfunction most often accompanies neuropathic changes seen in the sepsis. It is suggested that myopathic changes described as CIM and considered an important cause of muscle weakness develop due to denervation secondary to polyneuropathy and primarily reduction in striated muscle mass and muscle fibers (6).

Although CIP and CIM, which are considered to be major causes of muscle weakness in sepsis, can be found independently from each other, they are mostly seen together; this picture is termed CIPNM $(1,6,22,23)$.

Neuromuscular dysfunctions described as CIPNM considered to be developing in an inflammatory and catabolic background are frequently accompanied by a disruption of the balance between the protein synthesis rate and the protein degradation rate, decreased mitochondrial efficiency, decreased neuronal dysfunction in central/peripheral nervous system, inflammation, inactivation, and sleep patterns (12).

Approximately $17 \%$ of the total body protein is lost in the patients due to catabolic response developing in sepsis. Sepsis-induced protein loss basically indicates erosion in the skeletal muscles $(24,25)$.

Along with the increase in protein degradation in sepsis after unavoidable catabolism, protein synthesis also decreases due to the reduction in amino acid concentration. The amount of protein synthesis becomes limited with the use of decreased amino acids. Amino acid concentration, particularly glutamine, decreases in the skeletal muscles and plasma (26). The amount of intracellular amino acyl-tRNA transferase enzyme, which is responsible for protein synthesis of amino acids in ribosomes, is decreased in sepsis (25).
Degeneration of the skeletal muscles due to unavoidable protein loss causes a reduction in muscle mass, strength and activity $(4,5)$. Neuromuscular dysfunction becomes inevitable after a reduction in striated muscle mass.

It is suggested that the reduction in myofibers and sarcoplasmic proteins constituting fast-twitch fibers in striated muscles due to protein catabolism in sepsis is accompanied by myofiber atrophy, myosinolysis, muscle fiber necrosis and atrophic findings in contractile myosin filaments $(7,27)$.

Axonal degeneration that develops in sensorial and motor nerves manifests itself as the prolongation of the latency observable in electrophysiological studies. On the other hand, $\mathrm{CIM}$, another condition causing neuromuscular dysfunction and contributing to muscle weakness by accompanying CIP in sepsis, can only be diagnosed histologically. However, the decrease observed in CMAP amplitude is associated with prolongation of CMAP duration during electrophysiological recordings performed in the early stage of sepsis, and calls attention to muscle fiber membrane in the pathophysiology of CIPNM (20). It has been suggested that the decrease in CMAP amplitude and prolongation in CMAP duration can develop secondary to the dysfunction of energy-dependent sodiumpotassium pumps in the muscle (12). This energy change observed in muscle fibers seems to be similar to hibernation. In animals, during hibernation period, a decrease in striated muscle tension occurs at a rate of $23 \%$. Changes in intracellular amino acid metabolism, evident in glutamine, and a reduction in striated muscle mass are suggested to be similar to sepsis. Shrinkage occurring in the striated muscle cells resulting from dehydration due to decreased intramuscular glutamine concentration is suggested to cause changes in catabolic/anabolic behaviors in the striated muscle cells. Increased catabolism and a decline in intramuscular glutamine concentration lead striated muscle cells to decrease. Glutamine deficiency also has negative qualitative effects. Decreased intracellular glutamine concentration in the striated muscle causes cellular decrease and shrinkage. In the studies performed, cellular glutamine concentration is suggested to be a triggering factor in the response of catabolic/anabolic behavior models of the cells $(11,12,28)$.

It has been reported that decreased intracellular glutamine concentration is a necessary prerequisite for AMPK, which triggers the cellular energy program of intracellular glutamine and protein metabolism in the catabolic state (12). The available findings indicate that the decreased striated muscle and plasma glutamine levels in sepsis may be a remarkable reason for the development of neuromuscular dysfunction, and glutamine replacement in sepsis may also have positive effects regarding the prevention of neuromuscular dysfunction in addition to accepted favorable contributions as an immuno-nutrient. 
Striated muscles are considered to be the major tissue for glutamine homeostasis, which relatively becomes an essential amino acid in the sepsis. Since $80 \%$ of the total body amino acid pool is in the striated muscles, when protein catabolism increases in sepsis, glutamine is released from the skeletal muscles elementarily. While glutamine consumption/requirement increases, an unavoidable decrease in glutamine level and mass of the striated muscle is observed $(10,29)$.

Following endotoxin injection, it is observed that amino acid concentrations in the muscle and plasma decrease rapidly. It was shown that the release of glutamine from the muscle into plasma also increased simultaneously with the decrease in the plasma level of glutamine (10). Despite the rate of glutamine release from the muscle into plasma increasing during sepsis, the decrease in the plasma levels of glutamine cannot be prevented. Although the release of glutamine from the muscle tissue into the plasma increases, the basic reason for the decrease in plasma concentrations of glutamine is considered to be the increase of glutamine utilization in splanchnic tissues. After major surgical interventions in sepsis, it was demonstrated that glutamine uptake in the splanchnic tissues increased by up to $50-100 \%$ (10).

Glutamine is the most abundant non-essential amino acid found in the tissue and plasma (27,29-31). It also serves as an important precursor for biosynthetic events. It increases gluconeogenesis and protein synthesis. It plays an important role as a carrier of nitrogen and carbon. Glutamine inhibits protein degradation and is an important precursor for glutathione synthesis (32-34). Due to the increased glutamine requirement in sepsis, the non-essential amino acid glutamine relatively becomes an essential amino acid. In sepsis, glutamine that is mobilized from the striated muscles cannot meet the requirements and exogenous glutamine replacement is needed (9).

In addition, it was also reported that 11-40 g/day enteral glutamine supplementation in critically ill patients decreased morbidity and mortality (35). Similarly, parenteral glutamine supplementation at the dose of $0.3-0.5 \mathrm{~g} / \mathrm{kg} /$ day decreased hospital stay, infectious complications and MOF (36).

With acute and chronic replacement of enteral glutamine, it was shown that plasma levels of glutamine were maximal in the acute phase and especially in the first 30 and 45 minutes, but during the long-term replacement, the amount of glutamine stored in the liver and particularly in the gastrocnemius muscle increased without any change in plasma levels of glutamine. However, the extent to which this increased level of glutamine in the gastrocnemius muscle as a result of chronic glutamine replacement could affect the neuromuscular transmission disorder developing in the early stage of sepsis was not studied and there was no experimental model investigating how this change was reflected in the neuromuscular transmission disorders.
In our before experimental sepsis model, we showed that CMAP latency prolongation and decreased CMAP amplitude were the earliest electrophysiological findings and that they appeared in the first 24 hours of sepsis. (2) Similarly, as supported by our study findings, latency prolongation in the sepsis group seems to be statistically different (Table 1, Figure 1, 2).

Also in malignancies, glutamine stores are depleted similar to in sepsis due to metabolic stress and increased cell proliferation. In addition to known positive features of glutamine, experimental and clinical studies performed in malignant diseases with decreased blood and tissue levels of glutamine demonstrate that glutamine has a neuroprotective feature. It is suggested that glutamine exerts this effect with upregulation in Nerve Growth Factor (NGF) nRHA $(37,38)$. Peripheral neuropathies that develop in patients with malignant disease treated with neurotoxic chemotherapeutic drugs were shown to deteriorate in parallel with the decrease in the serum level of NGF $(37,39)$. Glutamine is also known to be protective against cardiac toxicity and neurotoxicity caused by chemotherapeutic agents. Glutamine particularly prevents peripheral neuropathy developing in the patients with metastatic breast cancer who receive stem cell transplantation and high-dose paclitaxel $(37,40,41)$. Furthermore, metabolites arising from glutamine metabolism were reported to prevent polyneuropathies induced by chemotherapeutic agents (42). Similar to the prevention of peripheral neuropathies developing due to chemotherapeutic agents by glutamine, the absence of increase in CMAP latency of the group in which glutamine replacement was performed is striking in our study.

In the sepsis group in which glutamine replacement was performed in our study, the absence of an increase in the replacement of a specific product, especially glutamine stored in the striated muscles, can provide favorable effects on neuromuscular transmission disorders seen in sepsis.

Recent studies have indicated that exogenous glutamine supplementation increased plasma glutamine levels but failed to prevent protein degradation $(43,44)$.

In addition, there is also evidence that glutamine supplementation might increase mortality. Glutamine is used by lymphocytes as a nitrogen and carbon precursor. It is suggested that glutamine supplementation increased lymphocyte proliferation and cytokine production in sepsis. Thus, in surgical, trauma and bone marrow transplantation patients, in addition to its favorable effects, glutamine might increase inflammatory response in sepsis and MOF patients. Severe inflammatory stimulation may stimulate proliferation of immune cells and increase glutamine requirement. Supplemented glutamine may also increase glutamine degradation by increasing lymphocyte proliferation and cytokine production (44-46). 
In their study published in 2013, Heyland et al. (47) and colleagues reported that glutamine significantly increased 28-day mortality. Then, glutamine supplementation for intensive care patients was criticized, especially in liver and kidney dysfunction. Today, timing of supplementation, dosage and relation with organ failure are under discussion. In Heyland's study, glutamine was used as enterally and parenterally at high doses. Besides this high dose, in the glutamine group with increased mortality, there was an increased number of organ failure patients, which might influence mortality rate together with the timing of initiation $(47,48)$.

Therefore, the complexity of the immune system and unpredictable interaction with glutamine should be taken into account during patient selection.

In contrast to those studies discussing glutamine supplementation in critically ill patients and sepsis, there are a limited number of experimental studies on glutamine supplementation in sepsis-induced polyneuromyopathy. In an experimental sepsis model published in 2005 it was reported that parenteral glutamine supplementation did not have any favorable impact on diaphragmatic function but had positive effects on biochemical and histopathologic parameters. Similar to our study model, they used CMAP to evaluate neuromuscular function, but in this study glutamine supplementation was parenteral and CMAP was measured from diaphragmatic muscles instead of M.gastrocnemius (49).

In our study model, we did not induce severe sepsis and glutamine was given only enterally. The degree of cecal puncture in the CLP model is closely related with the resulting endotoxemia and mortality. Sepsis severity and mortality increase with increasing puncture size. In our sepsis model, we used 22 $\mathrm{G}$ intracath for cecal puncture, which might lead to less severe sepsis with a lower mortality rate.

It could be concluded that it was necessary to avoid high doses of parenteral glutamine supplementation in MOF and shock patients, especially in the early period of critical illness. However, there are limited data on glutamine supplementation in sepsis-induced CIPNM. Therefore, in terms of our study results, glutamine supplementation might favorably influence neuromuscular conduction if patients are selected carefully. More detailed studies are needed in this field of investigation.

\section{CONCLUSION}

During the measurements performed at the end of 24 hours, it was observed that CMAP latency prolongation in the untreated sepsis group (Group I) was statistically significant, but there was no statistically significant difference in Group II in which enteral glutamine replacement was performed.
It is therefore observed that the use of glutamine prevents CMAP latency prolongation in the early stage of sepsis.

It was concluded that enteral glutamine replacement may be promising in the prevention of NMD in sepsis, but further studies are required.

Ethics Committee Approval: The study was initiated after obtaining approval from the Animal Ethics Committee of Ege University School of Medicine (Date: 28.07.2009, Number: 2009-77).

\section{Informed Consent: N/A.}

Peer-review: Externally peer-reviewed.

Author contributions: Concept - İ.C., A.R.M.; Design - İ.C., ARM.; Supervision - A.R.M., İ.C.; Resource - İ.C., A.R.M., O.B., K.D.; Data Collection and/or Processing - İ.C., A.R.M., K.D., O.B., M.U.; Analysis and/or Interpretation - İ.C., A.R.M., K.D., O.B., M.U.; Literature Search - İ.C., A.R.M., K.D., O.B.; Writing - İ.C., A.R.M., K.D., M.U., O.B.; Critical Reviews - İ.C., A.R.M., K.D., M.U., O.B.

Conflict of Interest: No conflict of interest was declared by the authors.

Financial Disclosure: The authors declared that this study has received no financial support.

\section{REFERENCES}

1. Ahlbeck K, Fredriksson K, Rooyackers O, Måbäck G, Remahl $\mathrm{S}$, Ansved T, et al. Signs of critical illness polyneuropathy and myopathy can be seen early in the ICU course. Acta Anaesthesiol Scand 2009;53:717-23. [CrossRef]

2. Cankayali I, Dogan YH, Solak I, Demirag K, Eris O, Demirgoren S, et al. Neuromuscular deterioration in the early stage of sepsis in rats. Critical Care 2007;11:R1. [CrossRef]

3. Cankayali I, Dogan YH, Solak I, Eris O, Demirgoren S, Moral AR. Effects of IgM-enriched immunoglobulin and fluid replacement on nerve conduction velocity in experimental sepsis. Turkish Journal of Trauma \& Emergency Surgery 2010; Ulus Travma Acil Cerrahi Derg 2010;16:9-14.

4. Brough W, Horne G, Blount A, Irving MH, Jeejeebhoy KN. Effects of nutrient intake. surgery. sepsis. and long term administration of steroids on muscle function. Br Med $J$ 1986;293:983-8. [CrossRef]

5. Boczkowski J, Dureuil B, Branger C, Pavlovic D, Murciano D, Pariente R, et al. Effects of sepsis on diaphragmatic function in rats. Am Rev Respir Dis 1988;138:260-5. [CrossRef]

6. Ricks E. Critical illness polyneuropathy and myopathy: a review of evidence and the implications for weaning from mechanical ventilation and rehabilitation. Physiotherapy 2007;93:151-6. [CrossRef]

7. Burnham EL, Moss M, Ziegler TR. Myopathies in critical illness: Characterization and nutritional aspects. $J$ Nutr 2005; 1818S-23S.

8. Latronico N, Shehu I, Seghelini E. Neuromuscular sequelae of critical illness. Curr Opin in Crit Care 2005;11:381-90. [CrossRef] 
9. Vermeulen MA, van de Poll MC, Ligthart-Melis GC, Dejong $\mathrm{CH}$, van den Tol MP, Boelens PG, et al. Spesific amino acids in critically ill patient-Exogenous glutamine/arginine: A common denominator. Crit Care Med 2007;35:S568-S76. [CrossRef]

10. Vesali RF, Klaude M, Rooyackers O, Wernerman J. Amino acid metabolism in leg muscle after an endotoxin injection in healthy volunteers. Am J Physiol Endocrinol Metab 2005;E360-E4. [CrossRef]

11. Häussinger D, Lang F, Gerok W. Regulation of cell function by the cellular hydration state. Am J Physiol 1994;67:E343-55.

12. Roth E, Oehler R. Hypothesis: Muscular glutamine deficiency in sepsis- a necessary step for a hibernation-like state. Nutrition 2010;26:571-4. [CrossRef]

13. Otero-Anton E, Gonzalez-Quintela A, Lopez-Soto A, LopezBen S, Llovo J, Perez LF. Cecal ligation and puncture as a model of sepsis in the rat: influence of the puncture size on mortality, bacteremia, endotoxemia and tumor necrosis factor alpha levels. Eur Surg Res 2001;33:77-9. [CrossRef]

14. Ritter C, Andrades M, Frota Junior ML, Bonatto F, Pinho RA, Polydoro M, et al. Oxidative parameters and mortality in sepsis induced by cecal ligation and perforation. Intensive Care Med 2003;29:1782-9. [CrossRef]

15. Bolton CF. Evidence of neuromuscular dysfunction in the early stage of the systemic inflammatory responce syndrome. Intensive Care Med 2000;26:1179-80. [CrossRef]

16. Bolton CF. Neuromuscular manifestations of critical illness. Muscle Nerve 2005;32:140-63. [CrossRef]

17. Tennilä A, Salmi T, Pettilä V, Roine RO, Varpula T, Takkunen O. Early signs of critical illness polyneuropathy in ICU patients with systemic inflammatory response syndrome or sepsis. Intensive Care Med 2000;26:1360-3. [CrossRef]

18. Cuddon PA, Murray M, Kraus K. Electrodiagnosis. In: Saltter DH, editor. Textbook of Small Animal Surgery Volume II, 3rd ed. Philadelphia; Saunders 2003:1108-17.

19. Bolton CF. Gilbert JJ. Hahn AF, Sibbald WJ. Polyneuropathy in critically ill patients. J Neurol Neurosurg Psychiatry 1984; 47:1223-31. [CrossRef]

20. Zochodne DW, Bolton CF, Wells GA, Gilbert JJ, Hahn AF, Brown JD et al. Critical illness polyneuropathy. A complication of sepsis and multiple organ failure. Brain 1987;110:819-41. [CrossRef]

21. Bolton CF. Sepsis and the systemic inflammatory response syndrome: neuromuscular manifestations. Crit Care Med 1996;24:1408-16. [CrossRef]

22. Routsi C, Gerovasili V, Vasileiadis I, Karatzanos E, Pitsolis T, Tripodaki E, et al. Electrical muscle stimulation prevents critical illness polyneuromyopathy: a randomized parallel intervention trial. Crit Care 2010;14:R74. [CrossRef]

23. Moss M, Yang M, Macht M, Sottile P, Gray L, McNulty M, et al. Screening for critical illness polyneuromyopathy with single nerve conduction studies. Intensive Care Med 2014;40:683-90. [CrossRef]

24. Plank LD, Connoly AB, Hill AG. Sequential changes in the metabolic response in severely septic patients during the first 23 days after onset of peritonitis. Ann Surg 1998;228:146-58. [CrossRef]
25. Vary TC, Lynch CJ. Biochemical approaches for nutritional support of skeleteal muscle protein metabolism during sepsis. Nutr Res Rev 2004;17:77-88. [CrossRef]

26. Askanazi J, Carpentier YA, Michelsen CB, Elwyn DH, Furst P, Kantrowitz LR, et al. Muscle and Plasma Amino Acids Following Injury Influence of Intercurrent Infection. Ann Surg 1980;192:1;78-85. [CrossRef]

27. Shou J. Glutamine. In: Zaloga GP. Ed. Nutrition in Critical Care. St. Louis. Missouri. USA: Mosby 1994;123-41.

28. Haussinger D, Roth E, Lang F, Gerok W. Cellular hydration state: an important determinant of protein catabolism in health and disease. Lancet 1993;341:1330-2. [CrossRef]

29. Wischmeyer PE. Glutamine: role in critical illness and ongoing clinical trials. Curr Opin Gastroenterol 2008;24:190-7. [CrossRef]

30. Gamrin L, Essén P, Forsberg AM, Hultman E, Wernerman J. A descriptive study of skeletal muscle metabolism in critically ill patients: free amino acids. energy-rich phosphates protein. nucleic acids. fat. water and electrolytes. Crit Care Med 1996;24:575-83. [CrossRef]

31. Wischmeyer PE, Kahana M, Wolfson R, Ren H, Musch MM, Chang EB. Glutamine reduces cytokine release, organ damage and mortality in a rat model of endotoxemia. Shock 2001;16:398-402. [CrossRef]

32. Singleton KD, Serkova N, Beckey WE, Wischmeyer PE. Glutamine attenuates lung injury and improves survival after sepsis. Role of enhanced heat shock protein expression. Crit Care Med 2005;33:1206-13. [CrossRef]

33. Morrison AL, Dinges M, Singleton KD, Odoms K, Wong HR, Wischmeyer PE. Glutamine's protection against celluler injury is dependent on heat shock factor. Am J Physiol Cell Physiol 2006;290:C1625-32. [CrossRef]

34. Wang WS, Lin JK, Lin TC, Chen WS, Jiang JK, Wang HS, et al. Oral glutamine is effective for preventing oxaplatininduced neuropathy in colorectal cancer patients. Oncologist 2007;12:312-9. [CrossRef]

35. Wernerman J. Glutamine supplementation. Ann Intensive Care 2011;18;1:25.

36. Vanek VW, Matarese LE, Robinson M, Sacks GS, Young LS, Kochevar M, et al. ASPEN position paper: parenteral nutrition glutamine supplementation. Nutr Clin Pract 2011;26:479-94. [CrossRef]

37. Apfel SC, Lipton RB, Arezzo JC, Kessler JA. Nerve growth factor prevents toxic neuropathy in mice. Ann Neurol 1991;29:87-90. [CrossRef]

38. Gwag BJ, Sessler FM, Robine V, Springer JE. Endogenous glutamate levels regulate nerve nerve growth factor mRNA expression in the rat dentate gyrus. Mol Cells 1997;7:425-30.

39. Cao Y, Kennedy R, Klimberg VS. Glutamine protects against doxorubicin-induced cardiotoxicity. J Surg Res 1999;85:178-82. [CrossRef]

40. Boyle FM, Wheeler HR, Shenfield GM. Glutamate ameliorates experimental vincristine neuropathy. J Pharmacol Exp Ther 1996;279:410-5.

41. Cascinu S, Catalano V, Cordella L, Labianca R, Giordani P, Baldelli AM, et al. Neuroprotective effect of reduced glutathione on oxaliplatin-base chemotherapy in advanced colorectal 
cancer: A randomized double-blind placebo-controlled trial. J Clin Oncol 2002;20:3478-83. [CrossRef]

42. Peltier AC, Russell JW. Recent advances in drug-induced neuropathies. Curr Opin Neurol 2002;15:633-8. [CrossRef]

43. Mori M, Rooyackers O, Smedberg M, Tjader I, Norberg A, Wernermann J. Endogenous glutamine production in critically ill patients: the effect of exogenous glutamine supplementation. Crit Care 2014;18:R72. [CrossRef]

44. Oudemans-van Straaten HM, van Zanten ARH. Glutamine supplementation in the critically ill : friend or foe? Crit Care 2014;18:143. [CrossRef]

45. Lin JJ, Chung XJ, Yang CY, Lau HL. A metaanalysis of trials using intention $t$ oto treat pirinciple for glutamine supplemantation in critically ill patients with burn. Burns 2013;39:565-70. [CrossRef]
46. Ziegler TR, Young LS, Benfell K, Scheltinga M, Hortos K, Bye R, et al. Ann Intern Med 1992;116:821-8. [CrossRef]

47. Heyland D, Muscedere J, Wischmeyer PE, Cook D, Jones G, Albert Met, al. A randomized trial of glutamine and antioxidans in critically ill patients. N Eng J Med 2013;368:1489-97. [CrossRef]

48. Mulherin DW, Sacks SS. Uncertainty about the safety of supplemantalglutamine: an editorial on "A randomized trial of glutamine and antioxidans in critically ill patients." Hepatobiliary Surg Nutr 2015;76-9.

49. Doruk N, Buyukakilli B, Atici S, Cinel I, Cinel L, Tamer L, et al. The Effect of Preventive Use of Alanyl-Glutamine on Diaphragm Muscle Function in Cecal Ligation and Puncture-Induced Sepsis Model. JPEN J Parenter Enteral Nutr 2005;29:36-43. [CrossRef] 